\title{
Tecnologia e sociedade: Álvaro Vieira Pinto e a filosofia do desenvolvimento social
}

\author{
Technology and society: Álvaro Vieira Pinto and the social development \\ philosophy
}

\section{Technologie et societe: Álvaro Vieira Pinto et la philosophie du développement social}

\author{
Técnología y sociedad: Álvaro Vieira Pinto y la filosofía del desarrollo social \\ Geovane Ferreira Gomes ${ }^{1}$ \\ Cidoval Morais de Sousa ${ }^{2}$ \\ Maria Cristina Piumbato Innocentini Hayashi ${ }^{3}$
}

Recebido em 18/10/2016; revisado e aprovado em 19/04/2017; aceito em 24/04/2017

DOI: http://dx.doi.org/10.20435/inter.v18i2.1421

\begin{abstract}
Resumo: O texto discute a relação entre tecnologia e desenvolvimento social. Retoma autores do pensamento social brasileiro até chegar à filosofia social de Álvaro Vieira Pinto, para quem a chegada da tecnologia estrangeira ao Brasil, apesar de promover benefício inicial incompleto, permitiu a formação de mão de obra necessária ao desenvolvimento. Serão analisados os efeitos da instalação de empresas de tecnologia em Jaguariúna, SP, e mostrada a aderência da teoria Vieira Pinto no desenvolvimento da cidade.
\end{abstract}

Palavras-chave: Álvaro Vieira Pinto; desenvolvimento social; tecnologia e sociedade.

Abstract: The text discusses the relation between technology and social development. It starts reading classic authors of Brazilian social thought until reach the social philosophy of Álvaro Vieira Pinto, to whom, the arrival of foreigner technology in Brazil, despite promoting an initial incomplete benefit, allowed the formation of a skilled workforce, needed to development. It will be analyzed the effects of the arrival of technology companies at Jaguariúna-SP, and to show the adherence of Vieira Pinto's theory in the city development.

Key words: Álvaro Vieira Pinto; social development; technology and society.

Résumé: Le texte traite de la relation entre la technologie et le développement social. Il commence à lire les auteurs classiques de la pensée sociale brésilienne jusqu'à atteindre la philosophie sociale de Álvaro Vieira Pinto, à qui, l'arrivée de la technologie de l'étranger au Brésil, en dépit de la promotion d'une prestation initiale incomplète, a permis la formation d’une main-d'œuvre qualifiée, nécessaire pour le développement. II sera analysé les effets de l'arrivée des sociétés de technologie a Jaguariúna-SP, et de montrer l'adhésion de la théorie de Vieira Pinto dans le développement de la ville.

Mots-clé: Álvaro Vieira Pinto; developpement social; technologie et societé.

Resumen: El artículo analiza la relación entre la tecnología y el desarrollo social. Retoma autores del pensamiento social brasileño para llegar a la filosofía social de Álvaro Vieira Pinto, para quien la llegada de la tecnología extranjera a Brasil, a pesar de la promoción de beneficio inicial incompleta, permitió la formación de mano de obra necesaria para el desarrollo. Se analizarán los efectos de la instalación de empresas de tecnología en Jaguariúna-SP, y la adherencia de la teoría Vieira Pinto en el desarrollo de la ciudad.

Palabras clave: Álvaro Vieira Pinto; desarrollo social; tecnología y sociedade.

\section{INTRODUÇÃO}

O objetivo deste texto é discutir a ideia de desenvolvimento socioeconômico brasileiro a partir do conceito de apropriação de tecnologia visando apontar ao menos uma possibilidade de

\footnotetext{
${ }^{1}$ Universidade Estadual de Mato Grosso do Sul (UEMS), Paranaíba, Mato Grosso do Sul, Brasil.

${ }^{2}$ Universidade Estadual da Paraíba (UEPB), João Pessoa, Paraíba, Brasil.

${ }^{3}$ Universidade Federal de São Carlos (UFSCar), São Carlos, São Paulo, Brasil.
} 
caminho a ser trilhado nessa direção ${ }^{4}$. Assim, a hipótese que norteou a pesquisa é que o domínio da tecnologia por meio da fabricação de produtos da Tecnologia da Informação e Comunicação (TIC) é capaz de proporcionar benefícios significativos à população, o que pode ser comprovado por meio de indicadores que mensurem as condições de vida nas cidades.

O texto inicia com a síntese de algumas teorias que explicam o Brasil e depois traça um paralelo com a discussão a respeito da tecnologia empreendida por Álvaro Vieira Pinto com base na filosofia social desse autor exposta no livro O conceito de tecnologia (2008). Em seguida, são analisados os efeitos da industrialização baseada na produção de equipamentos da TIC no município de Jaguariúna, SP, a partir da chegada desse tipo de indústria em seu território, buscando apresentar a aderência da teoria de Álvaro Vieira Pinto aos resultados de tal evento nessa localidade. Antes apresentaremos os materiais e métodos que utilizamos na elaboração deste trabalho.

\section{MATERIAL E MÉTODOS}

Na pesquisa original quatro etapas distintas merecem apresentação: o entendimento do desenvolvimento histórico da TIC no Brasil, o processo de interiorização do desenvolvimento paulista, pesquisa da legislação municipal de Jaguariúna e, por fim, consulta a indicadores socioeconômicos de desenvolvimento. Foi ainda entrevistado um ex-prefeito que nos ajudou a entender o momento político que orientou a virada econômica da cidade.

As duas primeiras etapas consistiram de consulta a referências bibliográficas. A terceira foi realizada na Câmara Municipal local e na Casa da Memória de Jaguariúna, onde foi possível consultar edições antigas do jornal da cidade. A quarta etapa foi empreendida consultando sites de instituições de referência em dados socioeconômicos, como o Instituto Brasileiro de Geografia e Estatística (IBGE), a Fundação Sistema Estadual de Análise de Dados (SEADE), e a Federação das Indústrias do Estado do Rio de Janeiro (FIRJAN).

Agora na revisão, como de certa forma buscávamos avaliar se os resultados anteriormente se perenizaram, fizemos uma revisão nos autores clássicos que discutiam o desenvolvimento brasileiro além de retornar aos indicadores socioeconômicos. Nas duas fases estudamos e reestudamos a questão filosófica da tecnologia tendo como referência o pensamento social de Álvaro Vieira Pinto. Nessa revisão esta foi, sem dúvida, nossa principal inspiração.

\section{EXPLICAÇÕES SOBRE O INSUCESSO BRASILEIRO}

A leitura dos estudos clássicos de Caio Prado Júnior (2000), Sérgio Buarque de Holanda (1997), Celso Furtado (1974; 2000), Gilberto Freyre (2002), Fernando Henrique Cardoso e Enzo Faletto (1970) fornecem os elementos que permitem uma discussão sobre as explicações para o insucesso econômico brasileiro.

A análise de Gilberto Freyre (2002) privilegia a sociedade patriarcal centrada na vida da casa grande e da senzala. Isso teria possibilitado a criação de um Brasil democrático no campo racial, fruto da facilidade do português em adaptar-se a outros povos e absorver deles os seus costumes. Essa característica viria do fato de o povo português ser de fato uma mistura que

\footnotetext{
${ }^{4}$ Esse artigo sintetiza e atualiza estudos realizados na dissertação de mestrado desenvolvida no Programa de PósGraduação em Ciência, Tecnologia e Sociedade da Universidade Federal de São Carlos (São Carlos, SP, Brasil), de autoria do primeiro autor, sendo os demais autores o orientador e a coorientadora.
} 
envolve desde negros da África, até loiros do norte e mesmo mouros e povos mediterrâneos, mostrando que raça não teria sido uma característica determinante na formação da sociedade portuguesa (FREYRE, 2002).

Dada sua posição peninsular, de quase exterioridade da Europa, Portugal se caracterizaria, portanto, como uma saída para aproximação com outros povos (HOLANDA, 1997), o que predisporia o português a se harmonizar com as diferenças étnicas, pois tampouco se negavam a misturar-se sexualmente. Soma-se a isso o fato de, por serem extremamente empreendedores em além-mar e terem uma pequena população, a mistura racial com os povos dominados ou recém-conhecidos se apresentava como uma solução para manterem-se ativos em tantos lugares diferentes do globo, pois estavam presentes simultaneamente na África, na Ásia e na América. O que limitaria a entrada de um estrangeiro no Brasil seriam diferenças de religião, sendo que o pertencimento à religião católica se apresentava como um pré-requisito essencial para que um estrangeiro pudesse se estabelecer no Brasil, tendo sido o elemento unificador da sociedade brasileira (FREYRE, 2002).

A influência desses fatores e a forma como se desenvolve a grande lavoura brasileira, por meio de concessões particulares que eliminariam os custos de implementação para a coroa portuguesa, dão forma a uma sociedade patriarcal, interiorizada, rural, extremamente tolerante na mistura racial, fundada no trabalho escravo, em que o poder privado confundia-se com o poder público, posto que o chefe político local era o próprio senhor do engenho (FREYRE, 2002).

Sérgio Buarque de Holanda (1997) tratou dos mesmos temas, mas, ao contrário da visão apaixonada de Gilberto Freyre (1959) que vê no Brasil uma democracia racial humanizada, em que o sucesso do empreendimento lusitano no Brasil se deve muito a essa força do português em suportar as condições adversas do clima (FREYRE, 2002), Holanda (1997) insiste que a sociedade patriarcal era a causa da dificuldade do Brasil em industrializar-se e desenvolver-se nos moldes europeus ou capitalistas.

O motivo é que a competitiva sociedade capitalista passou a exigir mais profissionalização e menos intimidade. Tal como já ocorrera na transição do trabalho artesanal para o trabalho industrial, o proprietário deveria ter se distanciado do negócio. Enquanto no primeiro, o trabalho era realizado por mestres com a colaboração de jornaleiros e aprendizes, no segundo essa era uma tarefa dos operários.

Teria sido necessária uma forma de gestão impessoal e hierarquizada que superasse o modelo tradicional de condução dos negócios pelo senhor de engenho, e que fosse apta para lidar com abstrações burocráticas e chefes intermediários em vez de vínculos de quase-parentesco e aproximação com o dono (HOLANDA, 1997). Portanto, devido à herança patriarcal, no início do século XX o Brasil ainda tinha dificuldades de adaptação a uma sociedade industrial que tentava se firmar no país. Essa herança permitia confundir o privado com o público e, ao entrar em contato com o mundo externo a ela, levou à formação de funcionários públicos que não discerniam as diferenças entre essas duas esferas. O resultado foi a constituição de gerações de funcionários que usavam a máquina pública como continuação da vida familiar, em vez de atuarem como um corpo burocrático técnico que zelaria pela coisa pública. Na visão de Holanda (1997), esses últimos eram representados por uma minoria.

Para Caio Prado Junior (2000), a história do Brasil é resultado do período das "grandes navegações" e, por esse motivo, é parte do desenvolvimento comercial do continente europeu. Por visar atingir ao oriente, não fazia parte do objetivo dos colonizadores se estabelecer ou povoar 
o continente americano. A América se apresentava inicialmente, de fato, como um estorvo, um grande território que dificultava a passagem para o rico mundo das especiarias da Índia.

A própria ocupação da América, sem um atrativo comercial interessante e que, dada a sua vazia imensidão, exigiria grandes aportes de pessoal de países que não contavam com população suficiente para lançar-se nessa empresa, era um problema de difícil solução. Se os espanhóis tiveram sorte de encontrar metais preciosos logo no século XVI no México e no Peru, o resto da América, tanto nas áreas de clima temperado, quanto nas demais zonas subtropical e tropical, não oferecia inicialmente vantagens ou produtos que valessem a pena ser desenvolvidos ou explorados localmente (PRADO JUNIOR, 2000).

Caio Prado Junior (2000) argumenta que esse cenário só mudaria na América temperada a partir do século XVII, quando, a partir de problemas político-religiosos e depois por questões econômicas no panorama da Inglaterra, a região passaria a receber um novo tipo de população.

Grupos religiosos movidos por um espírito que Max Weber (2007) retrata em seu clássico texto como tendo forte correlação com o espírito capitalista em ascensão, e um fluxo de pessoas expulsas pela nova ordem fundiária que se estabelecia, desenvolvem um modelo de ocupação da terra que Prado Junior (2000) evidencia como mais voltado ao povoamento que à pura exploração, e que, na prática, mantém fortes ligações culturais com a própria população que a originou, tornando-se, em essência, uma continuação dela.

Definido o povoamento do norte, Caio Prado Junior (2000) estabelece as condições que levaram ao povoamento da área tropical da América, portanto, do Brasil. Não tendo essas características culturais de povoamento, restaria aos trópicos produzir gêneros agrícolas que se apresentassem como comercialmente interessantes para serem comercializados na Europa, e voltados a atender um mercado capaz de enxergá-los como artigos de luxo (PRADO JUNIOR, 2000).

Prado Junior (2000) aponta que esse colonizador não viria como trabalhador, ao contrário daqueles que ocuparam a América do Norte $^{5}$, e sim como administrador de uma empresa baseada no trabalho escravo e no latifúndio e, então, criaria uma sociedade única, diferente dos padrões europeus. Essa sociedade então formada seria a base para se entender no que se tornou o Brasil e essencial para se mudar o estado presente por meio da alteração da estrutura de exploração então formada, que, durante os séculos seguintes, foi perpetuada por meio de sucessivas matrizes produtivas, iniciando na cultura do açúcar, tabaco e outros produtos, passando pela mineração, algodão até chegar ao período cafeeiro.

Do mesmo modo, Celso Furtado (2000) mostra que a ocupação da América, que ele enfatiza ser econômica, é a extensão do desenvolvimento comercial europeu, e que, à exceção da extração de metais preciosos nos Andes e no México, o interesse econômico no continente era mínimo. Nesse ponto, Portugal sai na frente aproveitando seu know-how da indústria da produção de açúcar, adquirido nas ilhas no Atlântico e materializado em um conhecimento capaz de produzir equipamentos para a indústria açucareira. Associados a parceiros holandeses na distribuição e comercialização do açúcar na Europa, os portugueses estabelecem no Brasil a agricultura baseada no latifúndio e na mão de obra escrava. Entretanto os holandeses não eram

\footnotetext{
${ }^{5}$ Prado Junior (2000) aponta que a ocupação das terras do sudeste dos Estados Unidos muito se assemelhava à grande lavoura brasileira, materializada nas assim chamadas Plantations. Contudo não se aprofunda no assunto, apesar de enfatizar a colonização de povoamento e não de exploração mais do nordeste norte-americano. Apesar desse vazio explicativo, o autor esclarece que os Estados Unidos apresentaram essas duas variantes de ocupação do território, ao contrário do Brasil teve apenas um modelo.
} 
apenas atravessadores, mas dominavam a técnica do refino do açúcar e o comércio no interior da Europa, além de serem financiadores do sistema de compra e venda. Ao possuírem o domínio do mercado consumidor, conseguiram tanto introduzir o açúcar produzido na ilha da Madeira, o qual era produzido em pequenas quantidades, quanto expandir o mercado para absorver a produção brasileira (FURTADO, 2000).

Esse sistema se desarticula a partir do momento que ocorre a dominação de Portugal pela Espanha. A reação holandesa que resultou na ocupação das terras produtoras do açúcar no nordeste brasileiro, e sua subsequente expulsão após terem absorvido todos os detalhes do processo produtivo, fizeram com que o capital e a tecnologia da produção da cana de açúcar fossem levados para o Caribe. Lá, os holandeses desenvolveram uma empresa do açúcar que derrubaria os preços internacionais do produto e colocaria em crise a estrutura portuguesa (FURTADO, 2000). Ou seja, o que os espanhóis não fizeram, isto é, o desenvolvimento agrícola de seus novos domínios, acabou sendo executado pelos holandeses e em uma região bem mais próxima da Europa.

Essa entrada do açúcar no Caribe expulsou os então colonizadores europeus que lá estavam, com a finalidade de povoamento, para as terras temperadas da América do Norte. Lá desenvolveram economia de subsistência e, ao se distanciarem da metrópole devido às crises políticas pelas quais a Inglaterra passava, desenvolveram o comércio com as próprias colônias inglesas do Caribe, vendendo não apenas seu excedente produtivo, mas suprindo os produtores de açúcar com madeira para armazenar o açúcar e animais para produzir a energia motriz dos engenhos (FURTADO, 2000).

Segundo Furtado (2000), o resultado é o desenvolvimento nos Estados Unidos de uma economia baseada no pequeno proprietário, não concentrada e não especializada, cujos itens de exportação eram relacionados às suas necessidades locais, consistindo uma unidade entre o que consumiam e o que comercializavam, ao contrário do que ocorria no Brasil. Na América temperada, a produção era voltada a um mercado interno que exportava o excedente, associado a um sistema de transporte marítimo desenvolvido localmente, caracterizando, portanto, uma área de povoamento, e não de exploração.

Furtado (2000) lembra que, para manter-se como Estado, Portugal fez pacto de proteção com a Inglaterra, à qual entrega o monopólio do comércio. A influência inglesa assume tal proporção que, mesmo após a independência do Brasil, gera dificuldades econômicas ao governo e incapacidade do poder central em resolver o problema. Só na segunda metade do século XIX, após a eliminação do passivo da colonização portuguesa junto à Inglaterra, e a partir da cultura do café, é que o Brasil encontraria elementos que impulsionariam a economia brasileira. Isso terminaria com o período colonial, apesar da manutenção de toda a estrutura escravocrata que já perdurava por séculos e que, em última instância, era o freio do desenvolvimento industrial brasileiro.

\section{O DESENVOLVIMENTO ALICERÇADO NA HERANÇA COLONIAL}

Materializada na incapacidade do incipiente polo industrial que se estabelece no começo do século XX em São Paulo de se alastrar por todo o território, associado a uma necessidade de buscar soluções que restaurem a capacidade de desenvolvimento do país após os efeitos do período colonial, as análises apresentadas salientam que a conexão existente entre o que o Brasil se tornou e seu passado colonial era o que impedia a industrialização local. 
Superada essa etapa de abordagem histórica, surge a necessidade de analisar a questão por meio de teorias que discutam e/ou apresentem caminhos de transformação possíveis. Esse novo ciclo de explicações se apoia na ideia de que é tarefa difícil industrializar um país da periferia do capitalismo. Três teorias dominaram a discussão a respeito da industrialização dos países periféricos na segunda metade do século XX: a teoria das trocas desiguais, a teoria da dependência e a teoria do capitalismo tardio. Todas as três podem ser aplicadas ao caso brasileiro.

Uma das ideias recorrentes na economia clássica é a da especialização. David Ricardo já apontou que países poderiam beneficiar-se mutuamente do comércio se cada um desenvolvesse uma vantagem na manufatura de um específico produto. É a chamada Teoria das Vantagens Comparativas. Por exemplo, ao comparar a produção de vinhos em Portugal com a de tecidos na Inglaterra, percebe-se que Portugal era mais produtivo para produzir vinhos e a Inglaterra se saía melhor manufaturando tecidos. Como cada país tem uma especialidade, as trocas comerciais beneficiariam a ambos (HUNT, 2005). Sendo assim, países com vocação agrícola ou de fornecimento de matérias-primas, como são os países da América Latina, estariam em condições de igualdade com os países industrializados. Como essa teoria não se mostrava compatível com a realidade, novas teorias se faziam necessárias.

Estudos conduzidos por Raul Prebisch na Comissão Econômica para América Latina e Caribe (CEPAL) apontam o contrário do proposto por Ricardo. Havia de fato um desequilíbrio nessas trocas comerciais, pois o preço das matérias primas diminuía quando comparado ao preço de produtos manufaturados. Causas como uma maior representatividade por parte dos trabalhadores dos países industrializados que possuíam uma capacidade maior em impedir decréscimos salariais que os trabalhadores dos centros fornecedores de commodities, ajudam a explicar tal fenômeno, que não havia sido considerado pelos economistas clássicos (PREBISCH, 1962). Por causa disso, o déficit comercial entre o centro e a periferia tende a aumentar continuamente, alargando o distanciamento econômico entre os países.

Em tese isso não deveria ocorrer, pois o aumento de produtividade da indústria, por questões relacionadas ao contínuo aumento da técnica, deveria abaixar o valor do produto industrializado frente ao primário, mais lento na introdução de melhorias no processo produtivo. No entanto, as novidades tecnológicas que a contínua busca por produtividade ocasiona, trazem um aumento da necessidade de bens de capital para sua produção e criam necessidades até então inexistentes. Tal análise permite concluir que, ao afetar a demanda, o consumo de itens tecnológicos acaba por influenciar os preços, beneficiando o país produtor de manufaturados. A saída desse círculo vicioso para os países periféricos, segundo Prebisch (1962), seria usar a mesma receita dos países centrais, ou seja, promover a industrialização.

Entretanto a industrialização não surtiu o mesmo efeito nos países periféricos, apesar de possuírem mercado, capital e até terem tido relativo sucesso em substituir importações por produção local. Ainda assim persistia a desigualdade social e o distanciamento dos países centrais, sendo necessária uma teoria específica para lidar com essa contradição e que encontrasse respostas além da pura economia. A explicação seria dada pela chamada teoria da dependência (CARDOSO; FALETTO, 1970).

A teoria da dependência aponta que as tentativas de atingir o desenvolvimento econômico dos países periféricos exportadores de matéria-prima por meio da industrialização eram arranjos políticos locais, ou seja, o que Cardoso e Faletto (1970, p. 141) chamaram de "internacionalização do mercado interno". Esse fenômeno se refere à concentração dos ganhos dessa industrialização 
nas mãos de um grupo reduzido, alinhado com os objetivos do capital estrangeiro que se beneficia desse processo, mas não compartilhado com a sociedade, causando o aumento da desigualdade social. O desenvolvimento local ainda estaria voltado ao benefício do capital externo.

Deixando evidente que já não seriam mais os interesses da classe agrário-exportadora aqueles que determinariam o caráter da dominação, apesar de entender que as formas de dominação existentes não haviam sido superadas, Cardoso e Faletto (1970) demonstram que o desenho de desenvolvimento que se estabelece no Brasil atrai uma solidariedade que vai além das classes dominantes, atingindo um espectro amplo de aceitação, que inclui de técnicos a burocratas e se materializa na produção de itens que atendem, sobretudo, a necessidade de produção e comercialização dos centros mais desenvolvidos.

Se não apenas as estruturas coloniais segurariam o desenvolvimento, outras forças deveriam entrar em ação para superar esse conjunto de dificuldades. Surgiria o papel desenvolvedor do Estado, que é tratado pela teoria do capitalismo tardio de João Manuel Cardoso de Mello. Essa teoria, que busca explicar a dificuldade de industrialização dos países periféricos, analisa a etapa monopolista do capitalismo e aponta que, por sua natureza, a entrada de competidores no país é dificultada (e por que não dizer, bloqueada), o que acaba por impedir que os países periféricos compitam em igualdade com os países centrais detentores dessas indústrias (MELLO, 1977).

Para reduzir a tensão entre interesses externos e internos, Mello (1977) entende que em vez de puramente econômica, como uma teoria keynesiana apontaria, o Estado deveria assumir uma postura política, cabendo a ele o papel de acomodar tanto a existência do capital monopolista internacional quanto o nacional, ambos necessários ao desenvolvimento. Ao primeiro interessava o dinamismo interno da economia e ao segundo, a necessidade de desenvolvimento da indústria local.

É interessante que essa discussão tenha ocorrido no último quarto do século XX, momento em que ocorre o desmantelamento do modelo fordista, o qual havia sido o responsável pela expansão do capitalismo no pós-guerra. Dessa época em diante, passa a ocorrer a instalação de indústrias em países periféricos, chamados, à época, de países do terceiro mundo. Conforme argumenta Lipietz (1988), a abertura de novos mercados consumidores protegidos foi o principal motivo dessa mudança, os quais também foram incentivados pela presença de baixos salários em mercados de trabalho fracamente regulamentados.

Lipietz (1988) aponta que, apesar dessas condições já existirem, tentativas anteriores não haviam funcionado mesmo com o interesse em industrialização por parte dos países periféricos. A chamada política de substituição das importações, apoiada no fechamento dos mercados por meio de barreiras alfandegárias e na aquisição de bens de produção voltados à garantia da produção local não se mostrou suficiente, pois se mostrou incapaz de reproduzir também a organização social dos países centrais.

Em primeiro lugar, não havia capacitação para operar as máquinas. O corpo gerencial e administrativo também não se mostrava preparado para suas novas funções ou necessidades organizacionais, e a produtividade ficou aquém daquelas dos países centrais. Além disso, como os ganhos não foram compartilhados com os trabalhadores, não houve aumento de consumo e, sem consumo de massa, não há produção em massa e, portanto, não é fordismo (LIPIETZ, 1988).

Os benefícios desse processo se concentraram nas famílias que estavam próximas dessa nova economia, mas como a produtividade era baixa, não se expandiu, pois o preço impedia uma alavancagem por meio de exportação, o que demandaria mais mão de obra e mais produção 
local. A tendência à concentração se repetia na história brasileira, mas agora na indústria, pois nem os ganhos eram distribuídos e tampouco a exportação crescia. Como apontou Lipietz (1988), a produtividade baixa tornava os produtos nacionais pouco atrativos; além disso, a importação do maquinário ocasionou desequilíbrio fiscal, resultado do déficit com o exterior e que se materializou em endividamento e inflação.

Essa situação, em que ocorre algum desenvolvimento industrial, mas sem a mesma organização social do centro, entenda-se, toda a construção de um Estado de Bem-Estar Social, Lipietz (1988) chama de subfordismo. Entretanto todos esses insucessos serviram ao menos para preparar a base que seria utilizada por gerações posteriores no desenvolvimento industrial brasileiro. Por exemplo, uma massa trabalhadora mais qualificada oriunda de camadas médias da população.

Essa visão vai ao encontro do pensamento social de Álvaro Vieira Pinto (2008) que entendia haver uma relação de proximidade entre industrialização e tecnologia. Assim, para o país que abrigasse tecnologia estrangeira atingir o estágio de desenvolvimento tecnológico seriam necessárias etapas anteriores de preparação, mesmo que aparentemente sem benefício. Sendo assim, se o desenvolvimento industrial trazia benefícios sociais, o domínio da tecnologia representaria a formação de condições capazes de promoverem transformações sociais, o que seria traduzido em melhoria das condições sociais e, com isso, diminuição da distância social-econômica entre países. Em outras palavras, a tecnologia se apresentaria como uma ferramenta de diminuição das desigualdades sociais. Vejamos como Álvaro Vieira Pinto concatena essas ideias.

\section{A TECNOLOGIA E A FILOSOFIA SOCIAL DE ÁlVARO VIEIRA PINTO}

A necessidade de desenvolver uma crítica social que permitisse ao Brasil superar a sua condição de país subdesenvolvido foi o que norteou o pensamento de Álvaro Vieira Pinto (MODESTO; ANSELMO, 2008). O domínio da tecnologia se transformaria em um fetiche ideológico que acabaria por estabelecer a dominação (KLEBA, 2006).

A superação dessa condição, na visão de Álvaro Vieira Pinto (2008), se daria por meio da obtenção de tecnologia por parte dos países subdesenvolvidos, mas não sem uma crítica dura a respeito do tema. Ou seja, primeiro era preciso reconhecer que o processo de subordinação da periferia derivava do controle da tecnologia pelos países centrais. Inicialmente na esfera material, pois observa que não há a absorção do estado da arte da tecnologia, mas do que se torna obsoleto no país desenvolvido. Em seguida, no caráter simbólico, no que chama de "endeusamento da tecnologia", situação na qual a dominação longe de representar ganho ao país a ela submetido, se reverte em benefício econômico de seus criadores. Além disso, em vez de patentear um ganho coletivo, a incorporação da tecnologia em países que efetivamente não a possuíam só ocorria na esfera do consumo, e apenas nas camadas economicamente privilegiadas.

Para superar o desconforto diante da maneira como a tecnologia se apresentava, Álvaro Vieira Pinto (2008) se valeu de duas ideias fundamentais. A primeira é que o Homem é um ser técnico e, por esse motivo, advogar a noção de uma era tecnológica transformadora, no caso a atual, sem considerar que a técnica sempre esteve presente na história humana, é não reconhecer que a técnica está na essência da formação humana. A segunda ideia, um desdobramento da anterior, é que, pelo fato da técnica ter sido parte fundamental do processo de desenvolvimento humano, torna-se ontológica. Por isso deve ser universal e beneficiar todas as pessoas por ser um "patrimônio da humanidade". Apesar disso, a tecnologia opera como um elemento 
de diferenciação e consequentemente de subordinação entre as nações, pois a diferenciação é resultado do processo de manutenção do controle da tecnologia, o que é feito pelos que a dominam.

Para elaborar seu raciocínio, Álvaro Vieira Pinto (2008) vai buscar, na teoria de Marx, alguma das bases de seu pensamento. Subjaz na teoria marxiana a noção de que o distanciamento da tecnologia seria uma forma de alienação; afinal a tecnologia seria parte da constituição dos homens como seres humanos. A superação da alienação, segundo Marx, ocorreria quando a classe social se constituísse em classe para si, etapa do desenvolvimento da consciência de classe que significa "superação dos obstáculos sociais" à realização das atividades "em conformidade com as potencialidades humanas" (RANIERI, 2006, p. 1). A consciência para si representa o passo final na superação da alienação, mas antes disso é necessária uma forma de reconhecimento preliminar. Nessa etapa inicial, Marx (1985) aponta que a classe social se reconhece como uma classe em si, mas por não ser ainda uma classe para si, é incapaz de lutar pelas suas demandas.

Nesse contexto e para construir seu pensamento, Álvaro Vieira Pinto (2008) parte do momento em que os sujeitos, apesar de possuírem outros atributos, tomam consciência de que não detêm a tecnologia. Mas ao menos já reconhecem isso, e esse momento se torna o ponto de partida da transformação. O reconhecimento dessa falta de conhecimento tecnológico para Vieira Pinto (2008) indica que é o momento em que os sujeitos formam a consciência de si.

Se para Hegel a transformação da consciência em si para consciência para si é resultado do reconhecimento do outro (PERRUSI, 1996), para Marx (1985) essa passagem assume novas formas, pois a burguesia se desenvolve como classe em duas fases distintas. A primeira é quando se forma ainda no regime feudal, e a segunda é quando, já constituída como tal, derruba o antigo regime. O mesmo processo em duas fases ocorreria com a classe trabalhadora. A primeira, o de constituição em si, é quando se estabelece uma condição comum que orienta os mesmos interesses, tendo isso sido produzido com a subordinação do trabalhador aos interesses do capital. O segundo momento corresponde ao momento do conflito contra a classe dominante. É o momento em que os "os interesses que defende se tornam interesses de classe" (MARX, 1985, p. 159). É na luta política, diz Marx, que a classe se estabelece como classe para si.

Superada a etapa da consciência de si, a etapa final seria a formação da consciência para si. Nesse momento, além do reconhecimento da consciência conforme proposto por Hegel, e à semelhança do conceito marxiano de classe, a luta da sociedade seria pela emancipação da tecnologia estrangeira, que Álvaro Vieira Pinto chama de alienígena. Essa etapa do desenvolvimento humano seria aquela em que a sociedade passaria a dominar a tecnologia e, como resultado, alcançaria autonomia política, econômica e social e faria uso da tecnologia como elemento de redução de suas próprias desigualdades sociais (PINTO, 2008).

A contribuição de Álvaro Vieira Pinto (2008) para essa discussão se encontra no seu conceito de "consciência para o outro". A ideia é que, na medida em que a tecnologia estrangeira penetra na esfera de consumo dos países periféricos, ela não entra apenas como mercadoria, mas também como elemento de dominação e produto cultural. Ao observar que a tecnologia que chegava aos países periféricos não era a mais recente, mas etapas já obsoletas de desenvolvimento tecnológico dos países centrais, que ainda seriam novidade na periferia, Álvaro Vieira Pinto (2008) argumenta que isto não é uma questão de adoção, mas de submissão à vontade de outrem.

Para aumentar a produtividade do processo comercial, instalam-se nos países periféricos alguns estabelecimentos industriais com a finalidade de diminuir os custos da transação, por 
exemplo, os custos de transporte. Durante essa etapa, a consciência já formada ainda é incapaz de trabalhar para seu próprio desenvolvimento, pois assume a consciência do outro, no caso, do centro, pois se materializa em uma forma de consumo que predomina apenas nas classes privilegiadas. Ainda não é o uso da tecnologia para emancipação social, mas como mercadoria, pois, por meio de seu consumo, as classes privilegiadas tentam imitar os costumes da metrópole, dado o "fascínio cultural" (PINTO, 2008, p. 266) que emerge nessa transação.

Nesse momento, a "tecnologia torna-se então o principal ingrediente com que o dominador irá compor a consciência 'para o outro' das massas subjugadas" (PINTO, 2008, p. 266); afinal, é o elemento de admiração que conecta uma sociedade a outra, e motivo de diferenciação social entre os que consomem a tecnologia e os demais. Cria-se, no país já subalterno, uma nova divisão: entre os que se beneficiam e consomem a tecnologia estrangeira e os demais, o que para alguns ainda menos informados recebe o nome de "desenvolvimento nacional" (PINTO, 2008, p. 271).

Mas, como produto cultural que é, apesar de a tecnologia proporcionar essa diferenciação inicial, traz o germe da mudança social, pois na medida em que seus produtos são apropriados, também se adquire a necessidade de se alterar as relações de desequilíbrio para poder aproveitá-la em sua plenitude.

Ao mesmo tempo em que se recebe a máquina, terá de ser desenvolvido localmente um conhecimento mínimo para operá-la e, lentamente, o país recebedor da tecnologia vai se capacitando. Dada à necessidade de expansão do capital, o maquinário e os produtos que chegam à periferia visando aumentar a acumulação acabam, ainda que em estágios muito iniciais, por desenvolver um conhecimento inicial mínimo a respeito da tecnologia. Citando o exemplo da produção de televisores, a introdução dessa produção no Brasil proporcionou a existência de um tipo de mão de obra até então inexistente, e necessária em seu processo de montagem e reparo (PINTO, 2008).

A etapa final desse processo seria o atingir de um desenvolvimento tecnológico voltado à melhoria das condições da população e apto a superar o que Álvaro Vieira Pinto (2008, p.40) chama de "maravilhamento" diante da tecnologia, o qual leva à adoção por imitação da técnica alienígena, e a uma formação precária de técnicos que se amestram em vez conhecer profundamente a tecnologia que produzem.

O caminho da superação é a educação, e seu fomentador, segundo Álvaro Vieira Pinto (2008), é o Estado. A ele cabem os esforços de investir adequadamente na educação a fim diminuir a distância dos países desenvolvidos. Considera a educação ferramenta de soberania nacional.

Da mesma forma que para Mello (1977), na teoria social de Álvaro Vieira Pinto (2008) o papel do Estado é fundamental, pois mesmo as classes sociais que seriam privilegiadas com o desenvolvimento tecnológico, e que ele identifica como as "elites dirigentes", não tomam essa dianteira, pois estavam submissas e atuavam como elementos de penetração das "forças culturais alienígenas" (PINTO, 2008, p. 279). Além disso, Álvaro Vieira Pinto enfatiza a necessidade de democratização do processo, pois é ele que legitimará a defesa da inteligência e da cultura nacional.

É possível observar que, para Álvaro Vieira Pinto (2008), a transição do subdesenvolvimento para o desenvolvimento passa pela absorção da tecnologia, e que essa absorção ocorre em etapas. A etapa inicial não seria suficiente para trazer conhecimento, entretanto é necessária à formação de mão de obra especializada que será utilizada no decorrer do processo de absorção tecnológica. Ao final desse processo, a sociedade se desenvolveria tecnologicamente e chegaria ao desenvolvimento econômico, tendo o Estado papel importante na proteção da qualidade 
da educação. Tal processo levaria à formação da consciência para si, ou seja, uma forma de consciência capaz de se voltar à solução de problemas específicos locais. Em vez dos homens se maravilharem com a tecnologia, as condições sociais locais seriam melhoradas.

A plenitude desse estágio está longe de ser atingido. O distanciamento tecnológico ainda persiste. Entretanto, a ação do Estado é capaz de propiciar benefícios à população ainda em estágios intermediários do processo de consolidação tecnológica. Os ganhos decorrentes do desenvolvimento a partir apenas da manufatura de produtos das Tecnologias de Informação e Comunicação (TIC) se mostram sólidos. Isso ocorreu no município de Jaguariúna, SP, a partir da chegada de fábricas de computadores e telefones celulares. Alguns desses ganhos e parte da dinâmica desse processo serão apresentados a seguir.

\section{O DESENVOLVIMENTO DE JAGUARIÚNA, SP, NA PERSPECTIVA DA FILOSOFIA SOCIAL DE ÁlVARO VIEIRA PINTO}

O município de Jaguariúna sofreu uma transição econômica nos anos 1990, tornando-se uma cidade hospedeira de empresas da TIC, Inicialmente, em 1994, foi instalada a Compaq, e em 1998 a empresa Motorola, seguida nos anos 2000 pela Commscope, JHT, Solectron e Flextronics. Todas manufaturavam produtos da TIC como computadores e telefones celulares. Inicialmente essas empresas operavam como montadoras, mas em alguns casos promoveram a difusão de conhecimento. A Motorola chegou a desenvolver dois modelos de telefones celulares, o C353 e o MotopebI U3. No primeiro caso, as parcerias foram com instituições brasileiras, especificamente com o Instituto Eldorado, sediado em Campinas e com o Centro de Estudos Avançados do Recife (CESAR), e, no segundo modelo, o desenvolvimento se deu com a equipe de Pesquisa e Desenvolvimento composta por funcionários brasileiros sediados em sua filial em Jaguariúna (FERREIRA, 2007).

Além disso, a Motorola desenvolveu parcerias com universidades brasileiras, como o INATEL (COR DO DINHEIRO..., 2004) e com a Universidade Federal de Pernambuco, local que abrigou o Programa de Residência em Software (SAMPAIO; LIMA, 2006). Tais ações, associadas à utilização de mão de obra especializada local, resultaram na criação do Brasil Test Center, setor da organização sediado no Brasil e que se tornou responsável por executar testes em telefones celulares, mesmo que tivessem sido desenvolvidos em outra unidade da empresa, localizada em outro país (ANGERAMI; MARTINS, 2007).

Há ainda um terceiro pilar de sustentação do modelo de Álvaro Vieira Pinto (2008) destinado ao desenvolvimento tecnológico presente no caso observado da cidade de Jaguariúna: a importância do Estado na impulsão desse processo. A proposição de que "o Estado deve formular e decidir sobre os programas educacionais e manter as universidades e institutos científicos das nações em desenvolvimento" (LEITE LOPES, s.d. apud PINTO, 2008, p. 277) é válida. No entanto é possível perceber, em Jaguariúna, uma pequena diferença do modelo de Álvaro Vieira Pinto, pois, nesse caso, ao menos parte do incentivo à educação foi promovido por uma empresa privada multinacional.

Dois aspectos merecem ainda ser destacados. O primeiro, segundo Álvaro Vieira Pinto (2008), é que há uma contradição no processo de acumulação do capital. Na sua necessidade de expansão ele vai à busca de novos consumidores, mas, ao introduzir seus produtos que "maravilham" esses novos consumidores, acabam por promover no país receptor a entrada "dos elementos da realidade social que o produziu, inclusive a ciência e a maquinaria utilizadas para

INTERAÇÕES, Campo Grande, MS, v. 18, n. 2, p. 129-144, abr./jun. 2017. 
gerá-lo" (PINTO, 2008, p. 274). Mais do que isso, o que se vê em Jaguariúna-SP é a participação do proprietário da tecnologia na difusão de conhecimento, mesmo que esse possa servir a seus concorrentes. Independentemente para quem venha a servir, a educação de qualidade será fundamental na produção de especialistas da tecnologia estrangeira que, assim, se universaliza.

O segundo aspecto é com relação ao papel do Estado nesse processo. Aparentemente distante, o poder público teve papel fundamental no estabelecimento desse empreendimento. E isso ocorreu nas três esferas: federal, estadual e municipal.

Dentre as ações na esfera federal, vale citar o estabelecimento, em 1991, da Lei de Informática (BRASIL, 1991) que determinou diversos benefícios fiscais às empresas que promovessem a produção de itens locais em vez de sua importação. Além disso, exigiu investimento em Pesquisa e Desenvolvimento de pelo menos $5 \%$ do faturamento das empresas, sendo que $2 \%$ deveriam obrigatoriamente ser gastos com universidades, institutos de pesquisa ou programas de informática. Conclui-se que parte do investimento da Motorola no INATEL e no CESAR veio dessa lei.

Na esfera estadual, houve um esforço grande em descentralizar o desenvolvimento econômico paulista por meio de novas estradas que privilegiavam centros urbanos distanciados da capital (NEGRI, 1996), e utilização de ICMS como forma de estimular a implantação de empreendimentos industriais da TIC no estado de São Paulo (SÃO PAULO, 1989).

Já o município de Jaguariúna organizou seu espaço físico por meio de um Plano Diretor criando espaço dedicado à implantação de indústrias (PREFEITURA MUNICIPAL, 1985), organizou suas finanças para dedicar parte da arrecadação ao desenvolvimento (PREFEITURA..., 1992) e benefícios fiscais para estimular a vinda de indústrias (PREFEITURA MUNICIPAL, 1991; 1996).

Vê-se, portanto, a importância do poder público e das instituições públicas e privadas no desenvolvimento. Falta apresentar os resultados desse processo.

\section{INDUSTRIALIZAÇÃO E OS EFEITOS NA CIDADE DE JAGUARIÚNA}

Até 1993, a taxa de crescimento de indústrias em Jaguariúna era menor que a média estadual. Entretanto, a partir de 1994, Jaguariúna se distancia dos números estaduais e apresenta um crescimento cerca de $30 \%$ maior que a média do estado. Essa mudança foi comprovada pelo aumento do consumo de energia elétrica industrial no mesmo período. Vale notar, entretanto, que o aumento de consumo de energia elétrica já havia iniciado no começo da década, indicando um provável aumento de consumo relacionado ao setor de serviços, que consome essa mesma categoria de energia elétrica (GOMES, 2010).

Como resultado, amplia-se o mercado de trabalho. Enquanto, na década de 1990, os indicadores do SEADE apontam para uma retração dos vínculos empregatícios na indústria no Estado de São Paulo, Jaguariúna apresentou crescimento crescente desses postos de trabalho em todos os anos entre 1992 e 1998. Por sua vez, essa atração de mão de obra elevou o salário médio da cidade. Houve períodos nos anos 2000, como apontaram os dados da SEADE, que esse índice de crescimento chegou a ser $40 \%$ maior que o índice de crescimento do estado. Por consequência, a taxa de crescimento populacional da cidade já era maior que a do estado desde os anos 1990 (GOMES, 2010).

O município foi beneficiado de várias formas a partir desse processo. Economicamente teve um significativo aumento do valor adicionado fiscal, o que impactou positivamente o crescimento da cota-parte do ICMS. 
Em outras palavras, aumentou-se muito a receita do município. Em meados dos anos 2000, a cidade de Jaguariúna, SP, possuía um PIB per capita quase oito vezes maior que a média brasileira (IBGE, 2007). Apesar de ser uma cidade com cerca de 40 mil habitantes nesse período, se tornou um polo exportador que superou a cidade de Campinas, SP, sede da região metropolitana em que está inserida (BOLETIM..., 2008).

Segundo a FIRJAN, em 2005, o Índice Firjan de Desenvolvimento Municipal (IFDM) de Jaguariúna era de 0,8603 , o que a colocava entre os municípios considerados como de alto desenvolvimento, posicionando-se como o 11 o melhor município do Brasil ${ }^{6}$. Na avaliação do mesmo indicador em 2013, o IFDM se manteve nesse patamar ${ }^{7}$, passando para 0,8622.

Finalmente, recebeu o prêmio Americas Award 2010 oferecido pela Organização das Nações Unidas (ONU) por ter conseguido erradicar a mortalidade infantil em 2009 (PORTAL..., 2010).

\section{CONSIDERAÇÕES FINAIS}

No momento em que as teorias explicativas que dominaram o século XX parecem já não dar conta da nova configuração política, econômica e social que predomina no Brasil ao início da segunda década do século XXI, a ideia central expressa neste trabalho foi a de mostrar que mudanças significativas ocorridas no Brasil na última década permitem lançar um novo olhar sobre este país.

Paradoxalmente, buscou-se em Álvaro Vieira Pinto, autor cujo pensamento foi construído na segunda metade do século XX, os elementos que permitem iniciar uma nova explicação de nosso país. Álvaro Vieira Pinto via, no domínio da tecnologia, a abertura para um país se desenvolver socialmente, a partir do momento que a tecnologia fosse voltada ao atendimento das necessidades socialmente colocadas.

A ideia de se utilizar esse autor nessa análise foi contrapor seu pensamento a outras teorias explicativas sobre o Brasil. O que foi possível perceber é que, de forma geral, as avaliações do Brasil, e aí se enquadram as abordagens clássicas de Gilberto Freyre, Sérgio Buarque de Holanda, Celso Furtado, Caio Prado Junior, mas também as de Fernando Henrique Cardoso e Enzo Faletto, tinham como propósito entender por que o Brasil se tornou o que é. Álvaro Vieira Pinto, mas também João Manuel Cardoso de Mello, de certa maneira buscaram entender o que era preciso ser feito para transformar o Brasil e colocaram no Estado papel significativo nesse processo.

Esse estágio ainda não foi atingido, entretanto, uma etapa intermediária da apropriação do conhecimento tecnológico já se faz presente no país, especificamente a manufatura de produtos da TIC. Apesar de não assegurar o conhecimento que levaria à autossuficiência tecnológica, essa etapa já capacita um número reduzido de profissionais e propicia recursos financeiros ao serviço público para ser aplicado em melhoria das condições sociais da população.

O exemplo do município de Jaguariúna-SP representa bem esse estágio intermediário, pois a presença de multinacionais da TIC proporcionou aumento na arrecadação que foi revertido em benefício da população. Vale notar que esse não foi um processo simples, posto que promoveu mudanças significativas no perfil da cidade. Não apenas a população aumentou, mas os

\footnotetext{
${ }^{6}$ Disponível em: <http://www.firjan.com.br/ifdm/consulta-ao-indice/ifdm-indice-firjan-de-desenvolvimentomunicipal-resultado.htm?UF=SP\&IdCidade=352470\&Indicador=1\&Ano=2005>. Acesso em: 21 abr. 2017.

${ }^{7}$ Disponível em: < http://www.firjan.com.br/ifdm/consulta-ao-indice/ifdm-indice-firjan-de-desenvolvimentomunicipal-resultado.htm?UF=SP\&IdCidade=352470\&Indicador=1\&Ano=2013>. Acesso em: 21 abr. 2017.
} 
rendimentos do trabalho na cidade, que por sua vez a tornava mais atrativa para outro tipo de população, interessada naqueles postos de trabalho que a TIC trazia para a cidade.

Mais importante até que essa mudança inicial é constatar, passados alguns anos da pesquisa original, que a cidade permanece atrativa. A cidade abriga, desde 2016, as obras do novo Broadcast Center da Sky - Operadora de TV por satélite ${ }^{8}$. A obra grandiosa e a tecnologia envolvida apontam que a cidade se consolidou como referência da indústria da TIC.

Além disso, manteve-se a qualidade de vida, o que pode ser comprovado pela manutenção do IFDM (na verdade ele até aumentou um pouco) e pela erradicação da mortalidade infantil, o que nos dá a segurança em afirmar que, se a ação política é fundamental no estabelecimento de boas instituições, uma vez alicerçadas, fica mais fácil a manutenção do que já foi conquistado.

Além disso, um conjunto de alianças com institutos de tecnologia do país deu forma a um corpo de profissionais capaz de desenvolvimentos da área da TIC.

Permanece o desafio de assegurar de fato a autossuficiência tecnológica, ou na linguagem de Álvaro Vieira Pinto, superar o estágio de consciência para o outro e atingir o estágio de consciência para si, na expectativa de que os ganhos dessa transformação estejam voltados para a correção de problemas sociais e que atinjam outros municípios.

Além disso, salienta-se a urgência de se repensar e rediscutir um Brasil que "pode dar certo". Tentando ir um pouco além da abordagem de Álvaro Vieira Pinto, torna-se necessário entender por que motivos o processo, em vez de ser contínuo e progressivo, está sujeito a barreiras que retardam ou simplesmente estacionam o desenvolvimento. O caso da TIC é típico, pois, apesar do surgimento de empresas nacionais capazes de projetar equipamentos dessa tecnologia, os preços praticados no Brasil e a quantidade ínfima de indústrias de produção de componentes utilizados nesses equipamentos sugerem uma estagnação no conhecimento, o que resulta em uma baixa produtividade do setor.

Longe de se apresentar como um único caminho ou uma solução mágica, uma inserção tecnológica pode colaborar na aceleração da diminuição das desigualdades sociais no Brasil.

\section{REFERÊNCIAS}

ANGERAMI, S.; MARTINS, I. O teste de Rosana. Época Negócios, n. 2, abr. 2007. Disponível em: <http:// epocanegocios.globo.com/Revista/Common/0,,ERT21976-16642,00.html>.

BOLETIM do Comércio Exterior da Região Metropolitana de Campinas (RMC) referente ao ano de 2007. Campinas: PUC-CAMPINAS, 2008. Disponível em: <http://www.puc-campinas.edu.br/midia/arquivos/2012/ jun/balanco-2007.pdf > Acesso em: 19 ago. 2015.

BRASIL. Lei n. 8.248, de 23 de outubro de 1991. Disponível em: <http://www.mct.gov.br/index.php/ content/view/6093.html\#inexistente>. Acesso em: 7 jan. 2010.

CARDOSO, F. H.; FALETTO, E. Dependência e desenvolvimento na América Latina: ensaio de interpretação sociológica. Rio de Janeiro: Ed. Guanabara, 1970.

COR DO DINHEIRO: incentivo da lei de informática beneficia universidades e centros de pesquisa brasileiros, como o Inatel, A. Revista Inatel educação + tecnologia + negócios, mar. 2004. Disponível em: <http://www. inatel.br/home/downloads2/doc_download/25-materia-da-capa>. Acesso em: 9 set 2015.

FERREIRA, F. A. C. Avaliação do Processo Produtivo Básico (PPB) na indústria de telefonia celular no período de 2000 a 2006. 2007. Monografia (Especialização Política e Gestão de C\&T: Tecnologia da Informação)

${ }^{8}$ Disponível em: <http://convergecom.com.br/teletime/22/03/2016/o-novo-broadcast-center-da-sky/>. Acesso em: 21 abr. 2017. 
- Centro de Desenvolvimento Sustentável/UnB, Brasília, 2007.

FREYRE, Gilberto. Casa-grande \& senzala. Rio de Janeiro: Record, 2002.

FREYRE, Gilberto. New world in the tropics. New York: Alfred A. Knopf, 1959.

FURTADO, Celso. Formação econômica do Brasil. São Paulo: Publifolha, 2000.

. O mito do desenvolvimento econômico. Rio de Janeiro: Paz e Terra, 1974.

GOMES, Geovane Ferreira. Da economia agrário-industrial à tecnologia da informação e comunicação: Jaguariúna-SP sob o olhar CTS. 2010. Dissertação (Mestrado em Ciência, Tecnologia e Sociedade) Universidade Federal de São Carlos, São Carlos, SP, 2010. Disponível em: <https://repositorio.ufscar.br/ bitstream/handle/ufscar/1053/3294. pdf?sequence=1\&isAllowed=y>. Acesso em: 21 abr. 2017.

HOLANDA, Sérgio Buarque de. Raízes do Brasil. São Paulo: Companhia das Letras, 1997.

HUNT, E. K. História do pensamento econômico: uma perspectiva crítica. São Paulo: Elsevier, 2005.

INSTITUTO BRASILEIRO DE GEOGRAFIA E ESTATí́sTICA (IBGE). Produto Interno Bruto dos Municípios 2002-2005. Rio de Janeiro: IBGE, 2007. Disponível em: <http://biblioteca.ibge.gov.br/visualizacao/livros/ liv37310.pdf>. Acesso em: 8 set. 2015.

KLEBA, J. Tecnologia, ideologia e periferia: um debate com a filosofia da técnica de Álvaro Vieira Pinto. Convergencia: Revista de Ciencias Sociales, v. 13, n. 42, p. 73-93, set./dez. 2006.

LIPIETZ, A. Miragens e milagres: problemas da industrialização no terceiro mundo. São Paulo: Nobel, 1988.

MARX, K. A miséria da filosofia. São Paulo: Global, 1985.

MELLO, J. M. C. de. O Estado brasileiro e os limites da "estatização". Ensaios de Opinião. (2+3) p. 14-16. Rio de Janeiro, 1977. Disponível em: <http://economidiando.blogspot.com.br/2011/09/o-estado-brasileiroe-os-limites-da.html>. Acesso em: 9 set 2015.

MODESTO, R. V.; ANSELMO, R. C. M. S. Álvaro Vieira Pinto e o ISEB: do pensamento social para o pensamento geográfico. In: ENCONTRO INTERNO, 8., e SEMINÁRIO DE INICIAÇÃO CIENTÍFICA DA UFU, 12., 2008. Anais..., Uberlândia, MG: UFU, 2008. p. 1-8.

NEGRI, B. Concentração e desconcentração industrial em São Paulo: 1880-1990. Campinas, SP: Editora da Unicamp, 1996.

PERRUSI, M. S. Hegel: o desdobrar-se da consciência (a dialética do reconhecimento). Cadernos do CTCH, v. 4, p. 63-72, 1996.

PINTO, A. V. O conceito de tecnologia. Rio de Janeiro: Contraponto, 2008. v. 1.

PORTAL DOS TRABALHADORES. Jaguariúna recebe prêmio internacional por zerar mortalidade infantil. 16 nov. 2010. Disponível em: <http://www.portaldostrabalhadores.com.br/news-pt-br/2010-11-16/ jaguariuna-recebe-premio-internacional-por-zerar-mortalidade-infantil/> Acesso em: 19 ago. 2015.

PRADO JUNIOR, Caio. Formação do Brasil contemporâneo. São Paulo: Publifolha, 2000.

PREBISCH, Raúl. El desarrollo econômico de la America Latina y algunos de sus principales problemas. Boletín Economico de America Latina, v. 7, n. 1, fev. 1962. Disponível em: <http://archivo.cepal.org/pdfs/ boletinEconomico/S6200332.pdf>. Acesso em: 6 set. 2015.

PREFEITURA MUNICIPAL [de] Jaguariúna. Lei Complementar n. 33, de 12 de janeiro de 1996.

. Lei Complementar n. 4, de 20 de dezembro de 1991.

Lei $n$. 708, de 2 de julho de 1985.

PREFEITURA DE JAGUARIÚNA: nada resiste ao trabalho. Jornal Gazeta Regional, 1992. Suplemento (Obras da Administração Tarcísio Chiavegato/Pedro Abrucês - 1989-1992).

RANIERI, J. Alienação e estranhamento: a atualidade de Marx na crítica contemporânea do capital. In: CONFERENCIA INTERNACIONAL KARL MARXY LOS DESAFIOS DEL SIGLO XXI, 3., Cuba, 2006. Anais..., 2006. 
Disponível em: <www.nodo50.org/cubasigloXXI/congreso06/conf3_ranieri.pdf>. Acesso em: 9 set 2015. SAMPAIO, A. C. A.; LIMA, J. M. Residência em software. Revista ProQualiti - Qualidade na Produção de Software, v. 2, n. 1, maio 2006. Disponível em: <http://jeltex.googlecode.com/svn/trunk/Jeltex/ Material\%20de\%20Leitura/UML/Qualidade\%20na\%20Produ\%C3\%A7\%C3\%A30\%20de\%20Sof\%20tware. pdf >. Acesso em: 9 set 2015.

SÃO PAULO. Secretaria da Fazenda. Lei n. 6.374, de 1 o de março de 1989. Disponível em: <http://info. fazenda.sp.gov.br/NXT/gateway.dll?f=templates\&fn=default.htm\&vid=sefaz_tributaria:vtribut>. Acesso em: 19 ago. 2015.

WEBER, M. A ética protestante e o espírito do capitalismo. São Paulo: Companhia das Letras, 2007.

\section{Sobre os autores:}

Geovane Ferreira Gomes: Engenheiro (FEI), Sociólogo (Unicamp), Mestrado em Ciência, Tecnologia e Sociedade (UFSCar), Doutorado em Sociologia (UFSCar), Professor do Curso de Ciências Sociais da Universidade Estadual de Mato Grosso do Sul (UEMS), Campus de Paranaíba.

E-mail: geovane@terra.com.br

Cidoval Morais de Sousa: Bacharel em Comunicação Social pela Universidade Estadual da Paraíba (1995), especialista em Sociologia na Universidade Federal da Paraíba (1997), doutor em Geociências pela Universidade Estadual de Campinas (2005). Professor efetivo da Universidade Estadual da Paraíba (UEPB), vinculado ao Programas de Pós-graduação em Desenvolvimento Regional. E-mail: cidoval@gmail.com

Maria Cristina Piumbato Innocentini Hayashi: Professora Titular em Ciência da Informação (UFSCar). Docente do Departamento de Ciência da Informação e dos Programas de Pós-Graduação em Ciência, Tecnologia e Sociedade (PPGCTS/UFSCar); Educação (PPGE/UFSCar); e Educação Especial (PPGEEs/UFSCar). Bacharel em Ciências Sociais pela Unesp/Araraquara (1979), mestre (1986) e doutora (1995) em Educação pela UFSCar. E-mail: dmch@ufscar.br 